\title{
The new Museum of the History of Medicine at the University of Zurich
}

In December 1990, the Museum of the History of Medicine at the University of Zurich, one of the most important and interesting medico-historical collections in the world, has been reopened in new rooms. While for many decades it was hidden in the tower of the main university building, it is now easily accessible, and open from Tuesday to Sunday, in the former Physiology Building (Rämistrasse 69, just on the left of the University). The Museum occupies the ground floor of this stately house, which was built in the 1880ies by the architect Otto Weber, a pupil of the famous Gottfried Semper.

In the first of the two articles that follow, Professor Beat Rüttimann expounds his philosophy of the connection of Medicine and Museum. In the second one, Dr. Christoph Mörgeli, the Curator of the Museum, describes the long and cumbersome road to the realization of the new Museum as well as his concept of presenting the evolution of medicine in an impressive and understandable way, from the primitive medicine-man on the one side and Hippocrates on the other to modern laboratory techniques and AIDS prevention. 